Chapter 4

\title{
Heat Pipes for Computer Cooling Applications
}

\author{
Mohamed H.A. Elnaggar and Ezzaldeen Edwan \\ Additional information is available at the end of the chapter \\ http://dx.doi.org/10.5772/62279
}

\begin{abstract}
There is an increasing demand for efficient cooling techniques in computer industry to dissipate theassociated heat from thenewly designed and developed computer processors to accommodate for their enhanced processing power and faster operations. Such a demand necessitates researchers to explore efficient approaches for central processing unit (CPU) cooling. Consequently, heat pipes can be a viable and promising solution for this challenge. In this chapter, a CPU thermal design power (TDP), cooling methods of electronic equipments, heat pipe theory and operation, heat pipes components, such as the wall material, the wick structure, and the working fluid, are presented. Moreover, we review experimentally, analytically and numerically the types of heat pipes with their applications for electronic cooling in general and the computer cooling in particular. Summary tables that compare the content, methodology, and types of heat pipes are presented. Due to the numerous advantages of the heat pipe in electronic cooling, this chapter definitely leads to further research in computer cooling applications.
\end{abstract}

Keywords: Heat pipes, Electronic cooling, Wick structure, Working fluids, Computer cooling applications

\section{Introduction}

Effective cooling of electronic components is an important issue for successful functionality and high reliability of the electronic devices. The rapid developments in microprocessors necessitate an enhanced processing power to ensure faster operations. The electronic devices have highly integrated circuits that produce a high heat flux, which leads to increase in the operating temperature of devices, and this results in the shortening of life time of the electronic devices [1]. Consequently, the need for cooling techniques to dissipate the associated heat is quiet obvious. Thus, heat pipes have been identified and proved as one of the 
viable and promising options to achieve this purpose prior to its simple structure, flexibility and high efficiency, in particularly. Heat pipes utilize the phase changes in the working fluid inside in order to facilitate the heat transport. Heat pipes are the best choice for cooling electronic devices, because depending on the length, the effective thermal conductivity of heat pipes can be up to several thousand times higher than that of a copper rod. The main perception of a heat pipe involves passive two-phase heat transfer device that can transfer large quantity of heat with minimum temperature drop. This method offers the possibility of high local heat removal rates with the ability to dissipate heat uniformly.

Heat pipes are used in a wide range of products such as air conditioners, refrigerators, heat exchangers, transistors, and capacitors. Heat pipes are also used in desktops and laptops to decrease the operating temperature for a better performance. Heat pipes are commercially presented since the mid-1960s. Electronic cooling has just embraced heat pipe as a dependable and cost-effective solution for sophisticated cooling applications.

\section{Thermal design power}

The thermal design power (TDP) has attracted the topmost interest of thermal solution designers, and it refers to the maximum power dissipated by a processor across a variety of applications [2]. The purpose of TDP is to introduce thermal solutions, which can inform manufacturers of how much heat their solution should dissipate. Typically, TDP is estimated as $20-30 \%$ lower than the CPU maximum power dissipation. Maximum power dissipation is the maximum power a CPU can dissipate under the worst conditions, such as the maximum temperature, maximum core voltage, and maximum signal loading conditions, whereas the minimum power dissipation refers to the power dissipated by the processor when it is switched into one of the low power modes. The maximum TDP ranges from 35 to $77 \mathrm{~W}$ for modern processors such as Intel ${ }^{\circledR}$ Core ${ }^{\mathrm{TM}}$ i5-3400 Desktop Processor Series [3], whereas the maximum TDP for modern notebook computers ranges from 17 to $35 \mathrm{~W}$ [4].

\section{Cooling methods of electronic equipments}

The air cooling is the most important technology that contributes to the cooling of electronic devices [5]. In the past, there were three main ways to cool the electronic equipment: (1) passive air cooling that dissipates heat using the airflow generated by differences in temperature, (2) forced air cooling that dissipates heat by forcing air to flow using fans, and (3) forced liquid cooling that dissipates heat by forcing coolants like water to pass [6]. The conventional way to dissipate heat from desktop computers was forced convection, using a fan with a heat sink directly. The advantages, such as simple machining, simple structure, and lower cost, have made heat sinks with plate fins very useful in cooling of electronic devices [7]. However, with the smaller CPU size and increased power as encountered in modern computers, the heat flux at the CPU has been significantly increased [8]. At the same time, restrictions have been imposed on the size of heat sinks and fans and on the noise level associated with the increased fan speed. Consequently, there has been a growing concern for improved cooling techniques 
that suit the modern CPU requirements. As alternatives to the conventional heat sinks, twophase cooling devices, such as heat pipe and thermosyphon, have emerged as promising heat transfer devices with effective thermal conductivity over 200 times higher than that of copper [9].

\section{Heat pipe theory and operation}

In order for heat pipe to operate, the maximum capillary pressure must be greater than the sum of all pressure drops inside the heat pipe to overcome them; thus, the prime criterion for the operation of a heat pipe is as follows

$$
\Delta P_{\mathrm{c}} \geq \Delta P_{1}+\Delta P_{\mathrm{v}}+\Delta P_{\mathrm{g}}
$$

where, $\Delta P_{\mathrm{c}}$ is the maximum capillary force inside the wick structure; $\Delta P_{1}$ is pressure drop required to return the liquid from the condenser to the evaporation section; $\Delta P_{\mathrm{v}}$ is the pressure drop to move the vapor flow from the evaporation to the condenser section; and $\Delta P_{\mathrm{g}}$ is the pressure drop caused due to the difference in gravitational potential energy (may be positive, negative, or zero, depends on the heat pipe orientation and a direction).

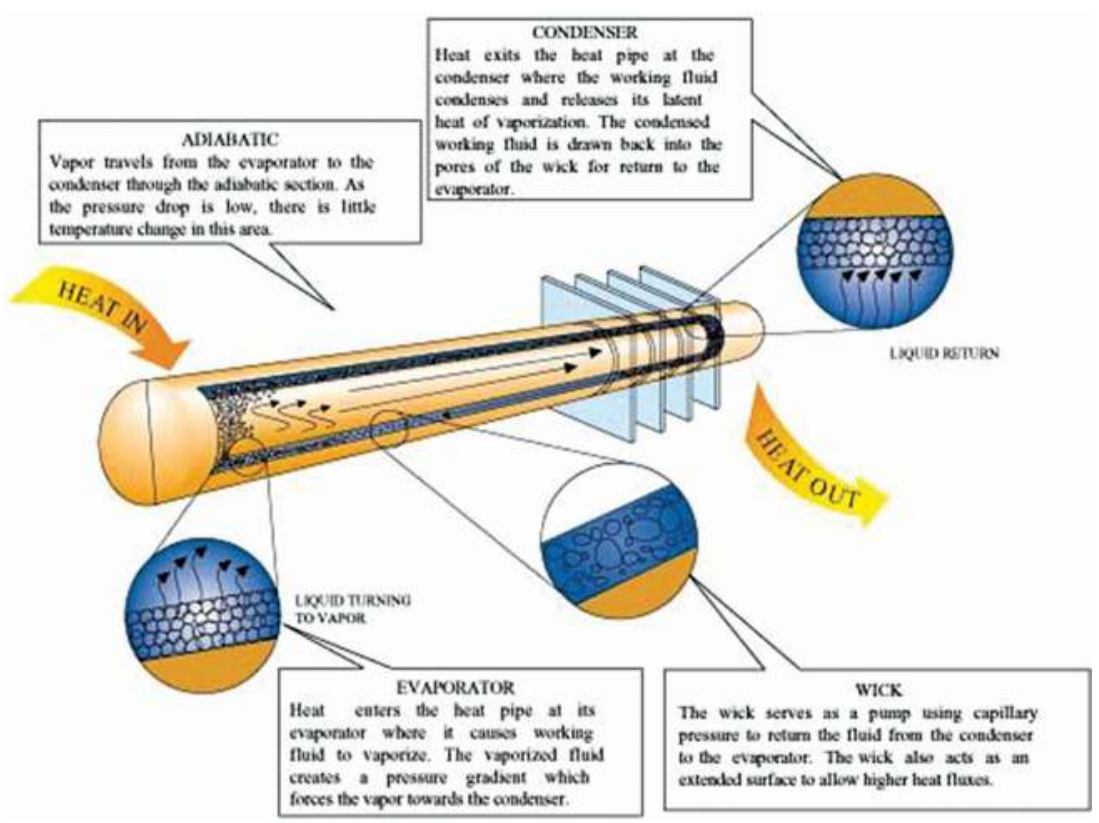

Figure 1. Heat pipe operation [10]. 
The basic steps of heat pipe operation are summarized as follows, with reference to Figure 1 [10]:

1. The heat added at the evaporator section by conduction through the wall of heat pipe enables the evaporation of working fluid.

2. The vapor moves from the evaporator section to the condenser section under the influence of vapor pressure drop resulted by evaporation of the working fluid.

3. The vapor condenses in the condenser section releasing its latent heat of evaporation.

4. The liquid returns from the condenser section to the evaporator section through the wick under the influence of capillary force and the liquid pressure drop.

The liquid pressure drop can be calculated from the empirical relation [11]:

$$
\Delta P_{l}=\frac{\mu_{1} L_{\mathrm{eff}} Q}{\rho_{1} K A_{\mathrm{w}} h_{\mathrm{fg}}}
$$

where $\mu_{1}=$ liquid viscosity, $L_{\text {eff }}=$ effective length of the heat pipe, $\varrho_{1}=$ liquid density, $K=$ wick permeability, $A_{\mathrm{w}}=$ wick cross-sectional area, and $h_{\mathrm{fg}}=$ heat of vaporization of liquid. The vapor pressure drop can be calculated from the following equation [12]:

$$
\Delta P_{\mathrm{v}}=\frac{16 \mu_{\mathrm{v}} L_{\mathrm{eff}} Q}{2\left(\frac{D_{\mathrm{v}}}{2}\right)^{2} A_{\mathrm{v}} \rho_{\mathrm{v}} h_{\mathrm{fg}}}
$$

where $\mu_{\mathrm{v}}=$ vapor viscosity, $\varrho_{\mathrm{v}}=$ vapor density, $D_{\mathrm{v}}=$ vapor space distance, and $A_{\mathrm{v}}=$ vapor core cross-sectional area.

The maximum capillary pressure $\Delta P_{\mathrm{c}}$ generated inside the wick region is given by the LaplaceYoung equation [13].

$$
\Delta P_{\mathrm{c}}=\frac{2 \sigma_{1}}{r_{\text {eff }}}
$$

where $\sigma_{1}$ is surface tension and $r_{\text {eff }}$ is the effective radius of the pores of the wick.

The maximum achievable heat transfer by the heat pipe can be obtained from the equation [11]:

$$
Q_{\text {max }}=\left(\frac{\rho_{1} \sigma_{1} h_{\mathrm{fg}}}{\mu_{l}}\right)\left(\frac{A_{\mathrm{w}} K}{L_{\mathrm{eff}}}\right)\left(\frac{2}{r_{\mathrm{eff}}}-\frac{\rho_{1} g L_{\mathrm{eff}} \sin \phi}{\sigma_{l}}\right)
$$


where $\varphi$ is the angle between the axis of the heat pipe and horizontal (positive when the evaporator is above the condenser and it is negative if vice versa).

At horizontal orientation $\varphi=0$, equation (5) will become

$$
Q_{\max }=\left(\frac{\rho_{l} \sigma_{l} h_{\mathrm{fg}}}{\mu_{1}}\right)\left(\frac{A_{\mathrm{w}} K}{L_{\text {eff }}}\right)\left(\frac{2}{r_{\text {eff }}}\right)
$$

\section{Advantages of heat pipe}

The heat pipe has many advantages compared with other cooling devices such as the following:

- The effective thermal conductivity is very high since the heat pipe operates on a closed twophase cycle. Therefore, it can transport large quantity of heat with very small temperature difference between evaporator and condenser sections.

- It can transfer the heat without any moving parts so that the heat pipe is calm, noise-free, maintenance-free, and highly dependable.

- Due to its small size and weight, it can be used in cooling electronic devices.

- It is a simple device that works in any orientation and transfers heat from a place where there is no opportunity and possibility to accommodate a conventional fan; for instance, in notebooks.

- Heat pipes demonstrate precise isothermal control because of which the input heat fluxes can be varied without having to make significant changes in the operating temperature [14].

- The evaporator and condenser work independently, and it needs only common liquid and vapor so that the size and shape of the region of heat addition are different from the region of heat dissipation, provided that the rate of evaporation of the fluid does not exceed the rate of condensation of the vapor. Thus, the heat fluxes generated over smaller areas can be dissipated over larger areas with lower heat fluxes.

\section{Heat pipes components}

To obtain sufficient information on a heat pipe, researchers should study its basic components, which play an important role in the efficiency of the pipe. Many researchers focused their research on the most important aspects of these components, such as the heat pipe container, the wick structure, and the working fluid. The studies of these components were through experimental and numerical analysis.

\subsection{The container or the wall of a heat pipe}

A container is a metal seal, which is capable of transferring heat through it to the working fluid. This metal has a good heat conductivity. Many factors affect the selection of the material of 
the container, e.g., wettability, strength to weight ratio, machinability and ductility, compatibility with external environment and working fluid, thermal conductivity, weldability, and porosity. The container material must possess high strength to weight ratio, it must be nonporous to avoid any diffusion of vapor particles and, at the same time, should ensure minimum temperature difference between the wick and the heat source owing to its higher thermal conductivity.

\subsection{Wick or capillary structure}

The wick structure is the most important component of a heat pipe. It is responsible for the return of liquid from the condenser section to the evaporator section by the capillary property, even against the direction of gravity. Thus, the presence of wick makes the heat pipes operate in all orientations. The grooved wick, sintered wick, and screen mesh wick are the most important types of wick studied abundantly. These wick types are used widely in the electronics industry and are detailed next.

\subsubsection{Metal sintered powder wick}

As shown in the Figure 2, this type of the wick has a small pore size, resulting in low wick permeability, leading to the generation of high capillary forces for antigravity applications. The heat pipe that carries this type of wick gives small differences in temperature between evaporator and condenser section. This reduces the thermal resistance and increases the effective thermal conductivity of the heat pipe.

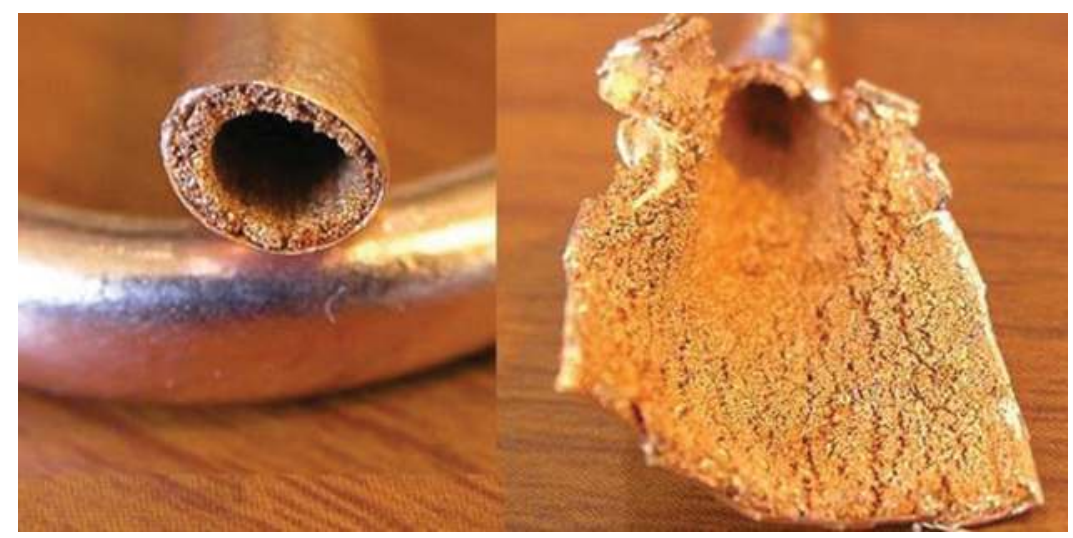

Figure 2. Metal sintered powder wick [15].

Leong et al. [16] investigated the heat pipe with sintered copper wicks. Flat plate heat pipes with rectangular porous wicks were fabricated using copper powder $(63 \mu \mathrm{m})$ sintered at 800 and $1000{ }^{\circ} \mathrm{C}$. They used mercury intrusion porosimetry and scanning electron microscopy (SEM) techniques to investigate the porosity and pore size distribution in these wicks. Results indicated a unimodal pore size distribution with most pore sizes distributed within $30-40 \mu \mathrm{m}$. 
Moreover, the cylindrical wicks fabricated by injection molding technique with the same binder and sintering temperature were also compared. The calculated permeability values of the rectangular wicks were as good as those of the commercially produced cylindrical wicks. Compared with the wire mesh, the sintered wicks had smaller pores and had the controllability of porosity and pore size to get the best performance.

\subsubsection{Grooved wick}

The grooved wick is shown in Figure 3; this type of wick generates a small capillary driving force, but is appropriate or sufficient for low power heat pipes, which operates horizontally or with the direction of gravity.

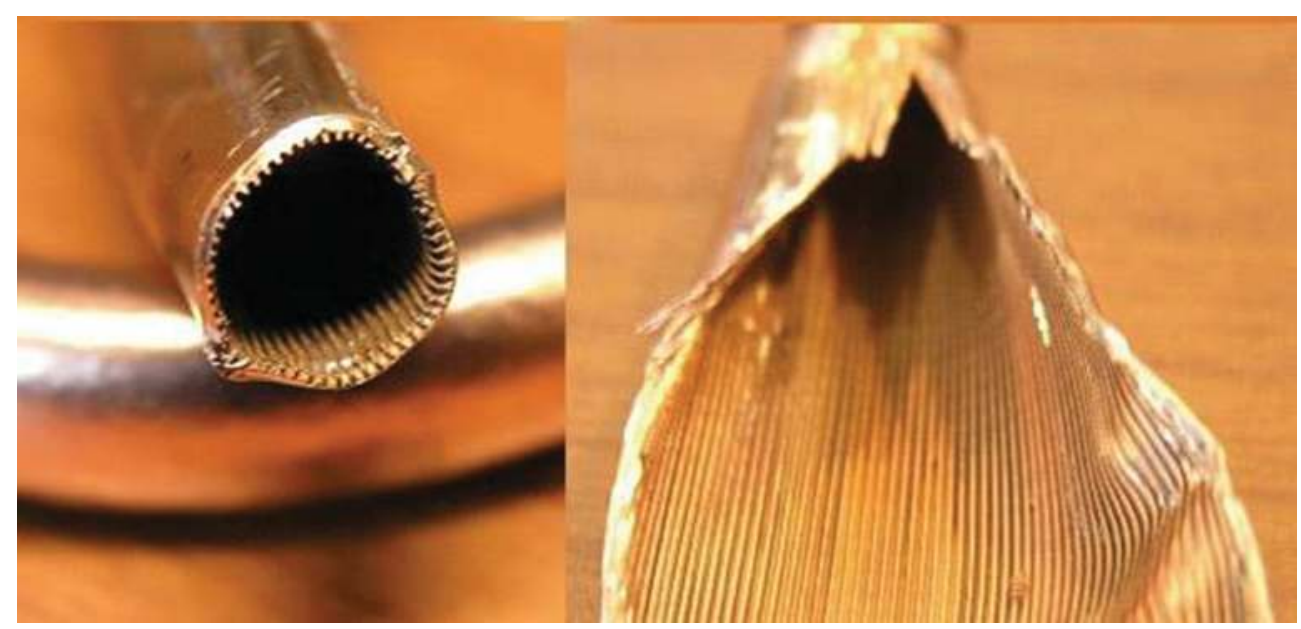

Figure 3. Grooved wick [15].

Zhang and Faghri [17] simulated the condensation on a capillary grooved structure. They investigated the impacts of surface tension, contact angle, temperature drop, and fin thickness using the volume of fluid (VOF) model. Results indicated that the contact angels and heat transfer coefficients decreased when temperature difference increased. Significant increase in the liquid film thickness was also observed upon the increase of the fin thickness. Ahamed et al. [18] investigated thin flat heat pipe with the characteristic thickness of $1.0 \mathrm{~mm}$, experimentally. A special fiber wick structure, which consisted of the combination of copper fiber and axial grooves as a capillary wick along the inner wall of the heat pipe, was used. The thin flat heat pipe was a straight one with rectangular cross section of $1.0 \mathrm{~mm} \times 5.84 \mathrm{~mm}$. The heat pipe was made from copper pipe of $4 \mathrm{~mm}$ diameter, and the working fluid was pure deionized water. Their observation showed that the maximum heat that could be transported by the thin flat heat pipe of $1.0 \mathrm{~mm}$ thickness was $7 \mathrm{~W}$. The thermal resistance of the heat pipe was 0.44 ${ }^{\circ} \mathrm{C} / \mathrm{W}$. The new fiber wick structure was also found to provide an optimum vapor space and capillary head for better heat transfer capabilities with less thermal resistance. 


\subsubsection{Screen mesh wick}

Figure 4 shows the screen mesh wick, which is used in many of the products, and they have demonstrated useful characteristics with respect to power transport and orientation sensitivity.

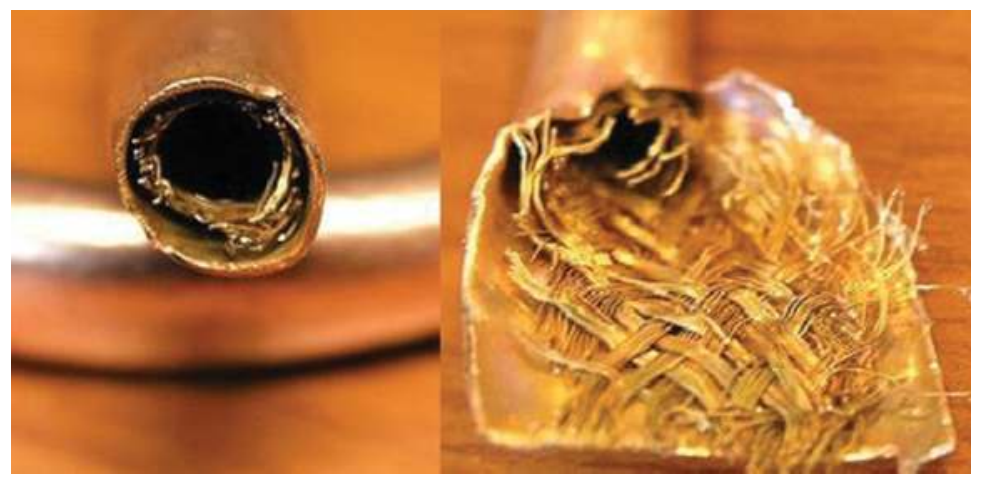

Figure 4. Screen mesh wick [15].

Wong and Kao [19] presented visualization of the evaporation/boiling process and thermal measurements of horizontal transparent heat pipes. The heat pipes had two-layered copper mesh wick consisting of 100 and/or 200 mesh screens, glass tube, and water as the working fluid. Under lower heat load conditions, the thickness of the water film was less than $100 \mu \mathrm{m}$, and the nucleate boiling was observed at $Q=40 \mathrm{~W}$ and $\mathrm{Q}=45 \mathrm{~W}$, respectively. Optimal thermal characteristics were determined for the wick/charge combination, which provided the smallest thermal resistance across the evaporator with lowest overall temperature distribution. In contrast to lower load conditions, the higher heat loads with small charge led to partial dry out in the evaporator. However, under a larger charge, there was limited liquid recession with increasing heat load, and the bubble growth was found to be unsustainable and bursting violently. Liou et al. [20] presented the visualization and thermal resistance measurement for the sintered mesh-wick evaporator in flat plate heat pipes. The wick thickness was between 0.26 and $0.80 \mathrm{~mm}$ with different combinations of 100 and 200 mesh screens. Results showed that the increasing heat load tend to decrease the resistance of the evaporation until partial dry out occurred. Following this, the resistance of the evaporation started to increase slowly. Low permeability of the wick limited the reduction of evaporation resistance and prompted dry out.

The studies of wick types have the following main conclusions:

- Metal sintered powder wick has a small pore size, resulting in low wick permeability. This leads to generation of high capillary forces for antigravity applications. The heat pipe that carries this type of wick produces small temperature differences between evaporator and condenser section. Therefore, the thermal resistance is reduced, and the effective thermal conductivity of the heat pipe is increased. 
- Grooved wick generates a small capillary driving force, which is appropriate or sufficient for low power heat pipes, that operates horizontally or with the direction of gravity.

- The efficiency of heat pipe with screen mesh wick depends on the number of layers and mesh counts used because it presents facilely variable characteristics whence heat transport and orientation sensitivity.

\subsection{Working fluids}

Selection of the working fluid depends primarily on the operating vapor temperature range. This is because the basis in the operation of the heat pipe is the process of evaporation and condensation of the working fluid. The selection of appropriate working fluid must be done carefully, taking into account the following factors [21]:

- must have very high surface tension;

- should demonstrate good thermal stability;

- wettability of wall materials and wick;

- should have high latent heat;

- should possess high thermal conductivity;

- should have low liquid and vapor viscosities; and

- it must be compatible with both wall materials and wick.

The most important property of the working fluid is high surface tension so that the heat pipe works against gravity as it generates high force of the capillarity characteristic. Table 1 summarizes the properties of some working fluids with their useful ranges of temperature [21].

\begin{tabular}{llll}
\hline Medium & Melting point $\left({ }^{\circ} \mathrm{C}\right)$ & Boiling point $\left({ }^{\circ} \mathrm{C}\right)$ & Useful range $\left({ }^{\circ} \mathrm{C}\right)$ \\
\hline Helium & -271 & -261 & -271 to -269 \\
Nitrogen & -210 & -196 & -203 to -160 \\
Ammonia & -78 & -33 & -60 to 100 \\
Acetone & -95 & 57 & 0 to 120 \\
Methanol & -98 & 64 & 10 to 130 \\
Flutec PP2 & -50 & 76 & 10 to 160 \\
Ethanol & -112 & 78 & 0 to 130 \\
Water & 0 & 100 & 30 to 200 \\
Toluene & -95 & 110 & 50 to 200 \\
Mercury & -39 & 361 & 250 to 650 \\
\hline
\end{tabular}

Table 1. Heat pipe working fluid properties. 
Distilled water is the most appropriate fluid for the heat pipes used for electronic equipment cooling. However, few researchers attempted to improve the thermal performance of the heat pipes by adding metal nanoparticles, which have good thermal conductors, such as silver, iron oxide, and titanium, to the distilled water in which the fluid is known as nanofluids. Some researchers looked into various ways to improve the performance of heat pipe through using different working fluids. Uddin and Feroz [22] experimentally investigated the effect of acetone and ethanol as working fluids on the miniature heat pipe performance. The experiments aimed to draw the heat from the CPU into one end of miniature heat pipes while providing the other end with extended copper fins to dissipate the heat into the air. The results illustrate that acetone had better cooling effect than ethanol. Fadhil and Saleh [23] reported an experimental study of the effect of ethanol and water as working fluids on the thermal performance of the heat pipe. The heat pipe was at the horizontal orientation during the experiments. The range of the heat flux changed within $2.8-13.13 \mathrm{~kW} / \mathrm{m}^{2}$, whereas all other conditions were constant. The results show that the thermal performance of the heat pipe with water as a working fluid was better than that with ethanol.

\section{Types of heat pipes}

\subsection{Cylindrical heat pipe}

Cylindrical heat pipe with closed ends is a common and conventional type of heat pipe. It involves circulation of working fluid and a wick to return the liquid. Basically, it consists of three sections, namely evaporator, adiabatic, and condenser, as shown in Figure 5.

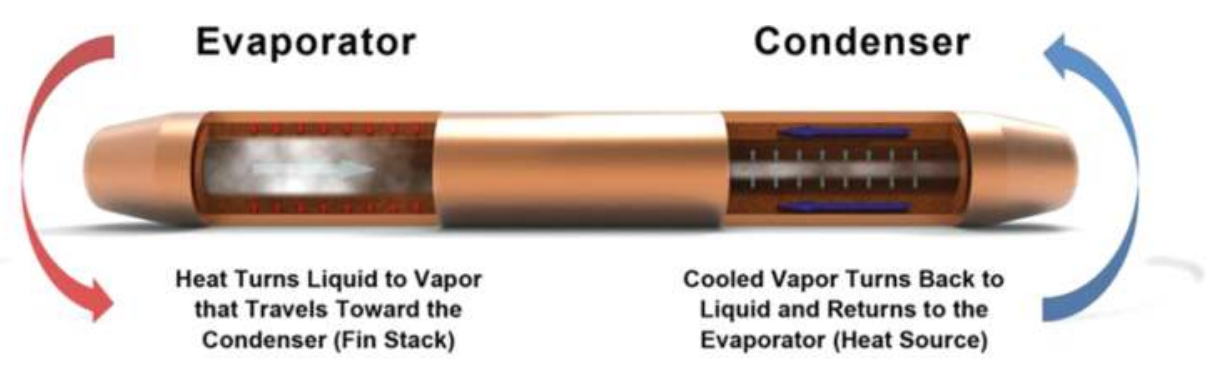

Figure 5. Cylindrical heat pipe [24].

El-Genk and Lianmin [25] reported on the experimental investigation of the transient response of cylindrical copper heat pipe with water as working fluid. The copper heat pipe with copper screen wick consisted of two layers of 150 meshes. Results showed that the temperature of the vapor was uniform along the heat pipe whereas the wall temperature drop was very small (maximum variation less than $5 \mathrm{~K}$ ) between the evaporator section and the condenser section. The steady-state value of the vapor temperature was increased when the heat input was increased or the cooling water flow rate was decreased. Said and Akash [26] experimentally 
studied the performance of cylindrical heat pipe using two types of heat pipes with and without wick, and water as the working fluid. They also studied the impact of different inclined angles, such as $30^{\circ}, 60^{\circ}$, and $90^{\circ}$, with the horizontal on the performance of heat pipe. Results showed that the performance of heat pipe with wick was better than the heat pipe without wick. The overall heat transfer coefficient was the best at the angle of $90^{\circ}$.

\subsection{Flat heat pipes}

Wang and Vafai [27] presented an experimental investigation on the thermal performance of asymmetric flat plate heat pipe. As shown in Figure 6, the flat heat pipe consists of four sections with one evaporation section in the middle and three condenser sections. The heat transfer coefficient and the temperature distribution were obtained. The results indicated that the temperature was uniform along the wall surfaces of the heat pipe, and the porous wick of the evaporator section had significant effect on the thermal resistance. The heat transfer coefficient was also found to be $12.4 \mathrm{~W} / \mathrm{m}^{2}{ }^{\circ} \mathrm{C}$ at the range of input heat flux $425-1780 \mathrm{~W} / \mathrm{m}^{2}$.

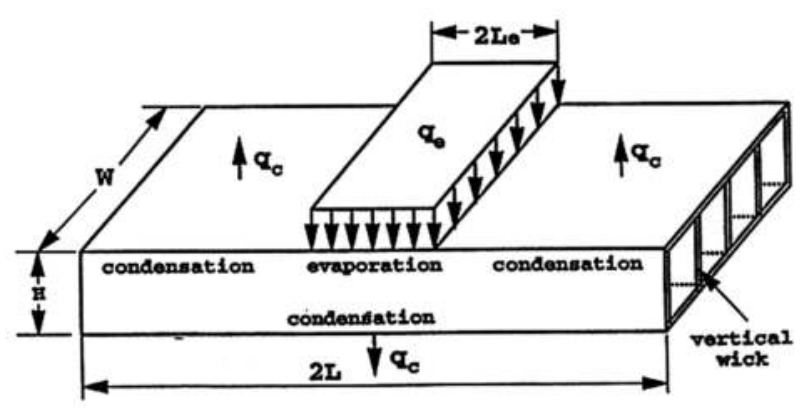

(a)

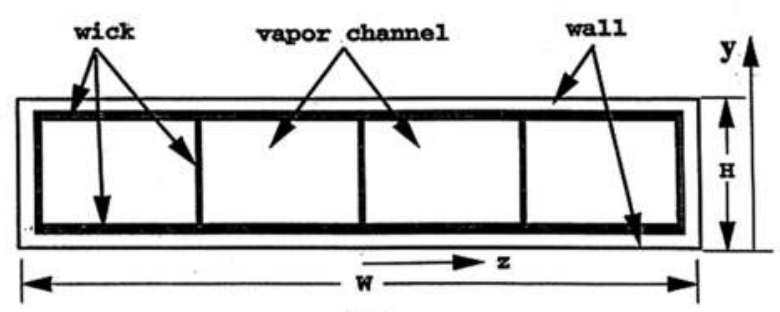

(b)

Figure 6. Schematic of the flat plate heat pipe: (a) geometry of the heat pipe and (b) cross-sectional view of the heat pipe [27].

Thermal performance of a flat heat pipe thermal spreader was investigated by Carbajal et al. [28]. They carried out quasi-three-dimensional numerical analysis in order to determine the field variable distributions and the effects of parametric variations in the flat heat pipe system. Investigations showed that flat heat pipe operating as a thermal spreader resulted in more 
uniform temperature distribution at the condenser side when compared to a solid aluminum plate having similar boundary conditions and heat input.

\subsection{Micro-heat pipes}

Micro-heat pipes differ from conventional heat pipes in the way that they replace wick structure with the sharp-angled corners, which play an important role in providing capillary pressure for driving the liquid phase. Hung and Seng [29] studied the effects of geometric design on thermal performance of star-groove micro-heat pipes. As shown in Figure 7, three different types of cross-sectional shapes of micro-heat pipes such as square star (4 corners), hexagonal star (6 corners), and octagonal star (8 corners) grooves with corner width w, were considered. Accordingly, the corner apex angle $2 \theta$ was varied from $20^{\circ}$ to $60^{\circ}$. At steady-state mode, one-dimensional mathematical model was developed to yield the heat and fluid flow characteristics of the micro-heat pipe. Results indicated that the geometrical design of the stargroove micro-heat pipes provides a better insight on the effects of various geometrical parameters, such as cross-sectional area, total length, cross-sectional shape, number of corners, and acuteness of the corner apex angle.

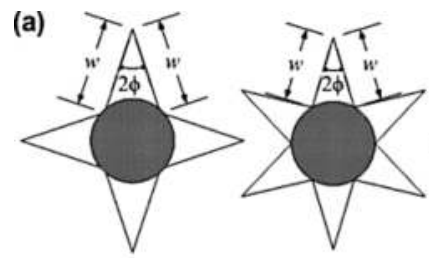

(i) (ii)

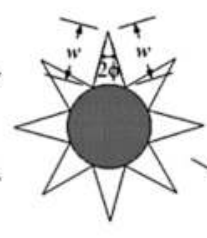

(iii)

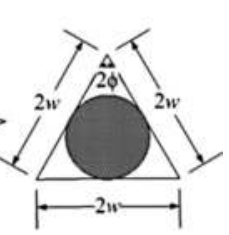

(iv)

(b)
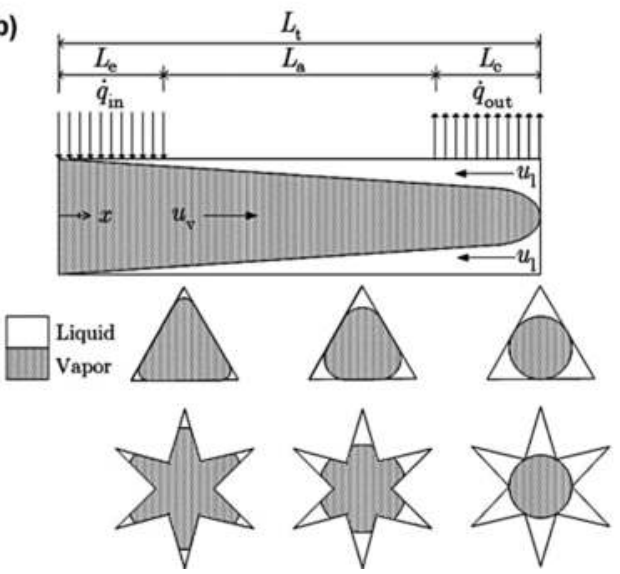

Figure 7. (a) Geometry of different cross-sectional shapes of micro-heat pipe: (i) square star groove, (ii) hexagonal star groove, (iii) octagonal star groove, and (iv) equilateral triangle. (b) Schematic diagram of optimally charged equilateral triangular and star-groove micro-heat pipes [29]. 


\subsection{Oscillating (pulsating) heat pipe}

Oscillating (pulsating) heat pipe (OHP) is one of the promising cooling devices in modern application that can transport heat in quick response in any orientation, where the oscillating phenomena offer an enhanced heat transfer mechanism as shown in Figure 8. The unique feature of OHPs, compared with conventional heat pipes, is that there is no wick structure to return the condensate to the heating section; thus, there is no countercurrent flow between the liquid and vapor [30]. The fluctuation of pressure waves drives the self-exciting oscillation inside the heat pipe, and the oscillator accelerates end-to-end heat transfer [31]. The pressure change in volume expansion and contraction during phase change initiates and sustains the thermally excited oscillating motion of liquid plugs and vapor bubbles between evaporator and condenser [32], this is because both phases of liquid and vapor flow has the same direction. The thermally driven oscillating flow inside the capillary tube effectively produces some free surfaces that significantly enhance the evaporating and the condensing heat transfer.

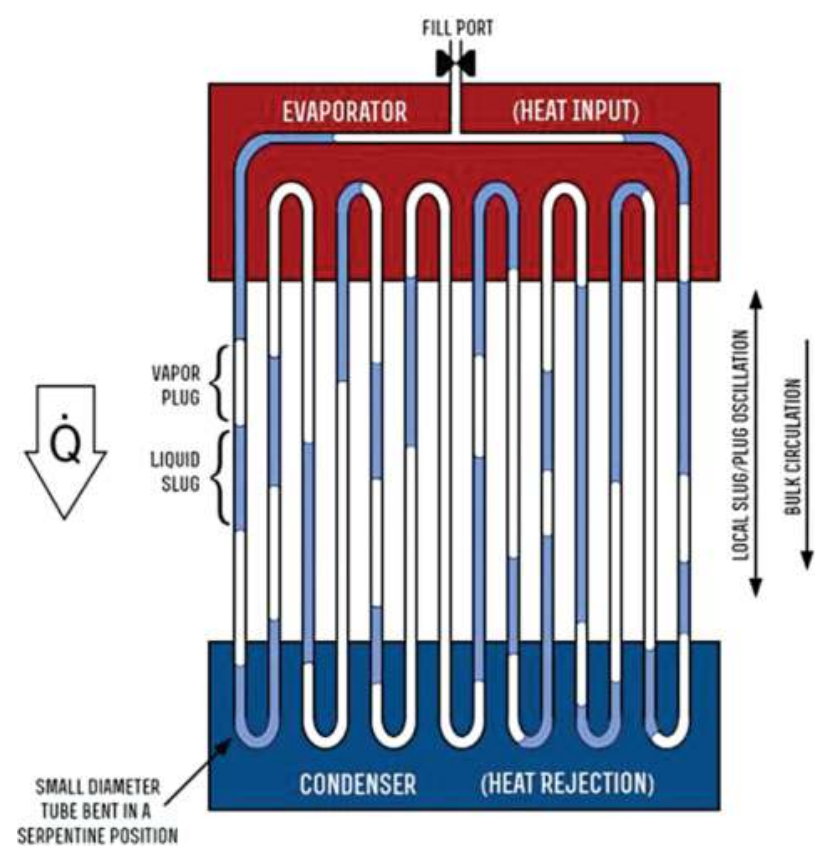

Figure 8. Schematic of an oscillating heat pipe [33].

Although many of researchers have considered the effect of OHP parameters on thermal performance, such as internal diameter, number of turns, filling ratio, and nanofluids, the development of comprehensive design tools for the prediction of OHP performance is still lacking [30]. Moreover, according to Zhang and Faghri [34], the previous theoretical models of OHPs were mainly lumped, one-dimensional, or quasi-one-dimensional, and many unrealistic assumptions were predominantly presented. 


\section{Mathematical modelling and numerical simulations}

Mathematical models of heat pipes are categorized into analytical method and numerical simulations. The analytical method validates the experimental and simulation results, which cannot be measured experimentally, such as pressure and velocity of working fluid inside the heat pipe. Numerical simulation is vital for investigating the thermal behavior of the working fluid inside the heat pipes and predicting the temperature of heat pipe wall, from which the thermal resistance and the amount of heat transmitted by the heat pipes can be calculated. Moreover, characterization of the liquid inside the wick, and predictions of the pressures and velocities of vapor and liquid, enables designing a highly efficient heat pipe for cooling electronic devices.

\subsection{Assumptions of the mathematical model}

The following assumptions were made for the mathematical formulation:

i. Vapor and liquid flows are assumed to be steady state, two-dimensional, laminar, and incompressible.

ii. The vapor is treated as ideal gas.

iii. There is no heat generation due to phase change and chemical reaction in the system.

iv. At the liquid-vapor interface, the liquid and vapor phases are coupled, and the vapor injection and suction are uniform [34].

v. The physical properties are constant.

\subsection{Governing equations}

Based on the above assumptions, the continuity, the momentum, and energy equations are listed as follows:

\subsubsection{Vapor region}

Continuity:

$$
\frac{u_{v}}{x}+\frac{v_{v}}{y}=0
$$

where, $u$ and $v$ are components of velocity in $x$ and $y$ directions, respectively.

Momentum: 


$$
\begin{gathered}
\rho_{v}\left(u_{v} \frac{u_{v}}{x}+v_{v} \frac{u_{v}}{y}\right)=\frac{-p}{x}+\mu_{v}\left(\frac{u_{v}^{2}}{x^{2}}+\frac{u_{v}^{2}}{y^{2}}\right) \\
\rho_{v}\left(u_{v} \frac{v_{v}}{x}+v_{v} \frac{v_{v}}{y}\right)=\frac{-p}{y}+\rho g+\mu_{v}\left(\frac{v_{v}^{2}}{x^{2}}+\frac{v_{v}^{2}}{y^{2}}\right)
\end{gathered}
$$

Energy:

$$
\rho_{v} c_{p}\left(u_{v} \frac{T}{x}+v_{v} \frac{T}{y}\right)=k_{v}\left(\frac{T^{2}}{x^{2}}+\frac{T^{2}}{y^{2}}\right)
$$

where, $g$ is the acceleration of gravity, $\rho_{v}$ vapor density, $\mu_{v}$ is the effective viscosity of vapor for laminar case is merely the dynamic viscosity, $c_{\mathrm{p}}$ specific heat, and $k_{\mathrm{v}}$ is thermal conductivity of vapor.

\subsubsection{Liquid wick region}

Continuity:

$$
\frac{u_{1}}{x}+\frac{v_{1}}{y}=0
$$

where, $u$ and $v$ are components of velocity in $x$ and $y$ directions, respectively.

Momentum:

$$
\begin{gathered}
\rho_{l}\left(u_{l} \frac{u_{l}}{x}+v_{l} \frac{u_{l}}{y}\right)=\frac{-P_{l}}{x}+\mu_{l}\left(\frac{u_{1}^{2}}{x^{2}}+\frac{u_{1}^{2}}{y^{2}}\right)+R_{x} \\
\rho_{l}\left(u_{l} \frac{v_{l}}{x}+v_{l} \frac{v_{l}}{y}\right)=\frac{-P_{l}}{y}+\rho_{l} g+\mu_{l}\left(\frac{v_{1}^{2}}{x^{2}}+\frac{v_{1}^{2}}{y^{2}}\right)+R_{y}
\end{gathered}
$$

$R_{x}$ and $R_{y}$ are distributed resistance components in $x$ and $y$ directions, respectively. A distributed resistance is a proper method to estimate the effect of porous media.

Energy: 


$$
\rho_{l} c_{p, l}\left(u_{l} \frac{T_{l}}{x}+v_{l} \frac{T_{l}}{y}\right)=k_{e}\left(\frac{T_{1}^{2}}{x^{2}}+\frac{T_{1}^{2}}{y^{2}}\right)+Q_{v}
$$

where, $g, \rho, \mu, C_{\mathrm{p}}, k_{\mathrm{e}}$, and $Q_{\mathrm{v}}$ are gravitational acceleration, density, dynamic viscosity, specific heat, effective thermal conductivity for liquid wick structure, and volumetric heat flux, respectively. Subscripts $\mathrm{v}$ and 1 refers to vapor and liquid regions, respectively. $k_{\mathrm{e}}$ is the effective thermal conductivity of the liquid wick structure for sintered powder wick, as expressed by [12]:

$$
k_{\mathrm{e}}=\frac{k_{1}\left[\left(2 k_{1}+k_{\mathrm{w}}\right)-2(1-\varphi)\left(k_{1}-k_{\mathrm{w}}\right)\right]}{\left(2 k_{1}+k_{\mathrm{w}}\right)+(1-\varphi)\left(k_{1}-k_{\mathrm{w}}\right)}
$$

For screen mesh wick, $k_{\mathrm{e}}$ is calculated from [12]:

$$
k_{e}=\frac{k_{l}\left[\left(k_{1}+k_{\mathrm{w}}\right)-(1-\varphi)\left(k_{1}-k_{\mathrm{w}}\right)\right]}{\left(k_{1}+k_{\mathrm{w}}\right)+(1-\varphi)\left(k_{1}-k_{\mathrm{w}}\right)}
$$

where, $\varphi$ is porosity and $k_{1}$ and $k_{\mathrm{w}}$ are thermal conductivity of liquid and wick material, respectively.

The steady-state thermal conductivity equation to predict the wall temperature is as follows:

$$
k_{s}\left(\frac{T_{s}^{2}}{x^{2}}+\frac{T_{s}^{2}}{y^{2}}\right)=0
$$

where, $k_{\mathrm{s}}$ is solid thermal conductivity and $T_{\mathrm{s}}$ is wall (surface) temperature.

\subsection{Boundary conditions}

At both ends of the heat pipe, $u_{\mathrm{v}}=v_{\mathrm{v}}=u_{1}=v_{1}=0$, and $\mathrm{P}_{\mathrm{v}}=\mathrm{P}_{1}$.

At the centerline of evaporator section, $v_{\mathrm{v}}=0, \frac{u_{\mathrm{v}}}{y}=0$, and $\frac{T}{y}=0$.

At the centerline of condenser section, $u_{\mathrm{v}}=0, \frac{v_{\mathrm{v}}}{y}=0$, and $\frac{T}{x}=0$.

At $r=R_{\mathrm{w}}, u_{\mathrm{l}}=v_{l}=0$.

At the adiabatic section, $\rho_{\mathrm{v}} v_{\mathrm{v}}=\rho_{1} v_{\mathrm{l}}=0$.

The continuity of mass fluxes in $y$ direction at the vapor-liquid interface yields $\rho_{\mathrm{v}} v_{\mathrm{v}}=\rho_{1} v_{1}=-\rho_{\mathrm{v}} v_{1}$ 
where, $v_{1}$ is the vapor injection velocity expressed as [35]:

$$
v_{1}=\frac{Q_{\mathrm{hp}}}{2 \rho_{\mathrm{v}} \pi R_{\mathrm{v}} L_{\mathrm{e}} h_{\mathrm{fg}}}
$$

Similarly, the continuity of mass fluxes in $x$ direction at the vapor-liquid interface yields $\rho_{\mathrm{v}} u_{\mathrm{v}}=\rho_{1} u_{1}=\rho_{\mathrm{v}} u_{1}$

where, $u_{1}$ is the vapor suction velocity as given in the study by Kaya and Goldak [35]:

$$
u_{1}=\frac{Q_{\mathrm{hp}}}{2 \rho_{\mathrm{v}} \pi R_{\mathrm{v}} L_{\mathrm{c}} h_{\mathrm{fg}}}
$$

The interface temperature $\left(\int_{T}\right)$ is calculated by the Clausius-Clapeyron equation, assuming the saturation temperature $\left(T_{0}\right)$ and vapor pressure $\left(P_{0}\right)$ at the liquid-vapor interface [36]:

$$
\int=\frac{1}{\frac{1}{T_{0}}-\frac{R}{h_{f g}} \ln \left(\frac{P_{v}}{P_{0}}\right)}
$$

For the solid-liquid interface:

At the evaporator part, $K_{\mathrm{e}} \frac{T_{1}}{y}=k_{\mathrm{s}} \frac{T_{\mathrm{s}}}{y}$

At the condenser part, $K_{\mathrm{e}} \frac{T_{1}}{x}=k_{\mathrm{s}} \frac{T_{\mathrm{s}}}{x}$

where $K_{\mathrm{e}}$ is the effective thermal conductivity of the liquid wick region, and $K_{\text {eff }}$ is the effective thermal conductivity of the whole heat pipe.

At the external heat pipe wall $=\left(\begin{array}{c}\text { Evaporator } k_{\mathrm{s}} \frac{T}{y}=q_{\mathrm{e}} \\ \text { Adiabatic } \frac{T}{y}=\frac{0 \wedge T}{x}=0 \\ \text { Condenser }-k_{\mathrm{s}} \frac{T}{x}=h\left(T_{\mathrm{s}}-T_{\mathrm{a}}\right)\end{array}\right)$

where, $h$ is convection heat transfer coefficient, and $T_{\mathrm{w}}$ and $T_{\mathrm{a}}$ are wall surface and ambient temperatures, respectively.

Mistry et al. [37] carried out two-dimensional transient and steady-state numerical analysis to study the characteristics of a cylindrical copper-water wicked (80 mesh SS-304 screen) heat pipe with water as a coolant at a constant heat input. Finite difference and Euler's explicit method (marching scheme) was used to solve the governing equations. As shown in Figure 9, a two-dimensional computational study using the concept of a growing thermal layer 
in the wall and the wick region was carried out. The transient axial temperature distributions were measured, and all the three sections of the heat pipe were compared with the numerical solution of the developed two-dimensional model. The time required to reach steady state was obtained. The transient and steady-state predictions of temperatures from the twodimensional model were in close agreement with the experimentally obtained temperature profiles.

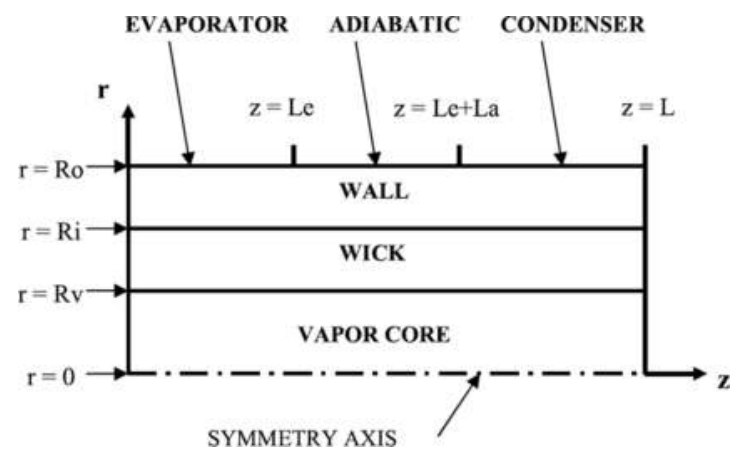

Figure 9. Coordinate system of the heat pipe [38].

Table 2 summarizes and compares some mathematical studies on heat pipes in terms of model, methodology, wick structure, orientation, and types of heat pipes.

\begin{tabular}{|c|c|c|c|c|c|c|}
\hline Author & Model & Method & Type & Wick structure & Orientation* & Regime $^{* *}$ \\
\hline Mistry et al. [37] & $2 \mathrm{D}$ & $\begin{array}{l}\text { Numerical, finite } \\
\text { difference }\end{array}$ & Micro & Screen mesh & $\mathrm{H}$ & $\mathrm{T}, \mathrm{SS}$ \\
\hline Maziuk et al. [38] & $1 \mathrm{D}, 2 \mathrm{D}$ & $\begin{array}{l}\text { Analytical, software } \\
\text { development }\end{array}$ & $\begin{array}{l}\text { Flat } \\
\text { miniature }\end{array}$ & $\begin{array}{l}\text { Copper sintered } \\
\text { powder }\end{array}$ & I & SS \\
\hline Suman et al. [39] & $1 \mathrm{D}$ & Analytical & Micro & Grooved & $\mathrm{H}$ & $\mathrm{T}$ \\
\hline Zhu and Vafai [34] & $2 \mathrm{D}$ & Analytical & Cylindrical & Porous media & $\mathrm{H}$ & SS \\
\hline Noh and Song [40] & $2 \mathrm{D}$ & $\begin{array}{l}\text { Numerical, finite } \\
\text { volume }\end{array}$ & Cylindrical & Screen mesh & $\mathrm{H}$ & $\mathrm{T}$ \\
\hline $\begin{array}{l}\text { Mahjoub and } \\
\text { Mahtabroshan [41] }\end{array}$ & $2 \mathrm{D}$ & $\begin{array}{l}\text { Numerical, finite } \\
\text { volume }\end{array}$ & Cylindrical & Porous media & $\mathrm{H}$ & SS \\
\hline Kaya and Goldak [36] & $3 \mathrm{D}$ & $\begin{array}{l}\text { Numerical, finite } \\
\text { element method }\end{array}$ & Cylindrical & Screen mesh & $\mathrm{H}$ & SS \\
\hline Ranjan et al. [42] & $3 \mathrm{D}$ & Numerical, macro model ${ }^{* *}$ & Flat & $\begin{array}{l}\text { Sintered, screen } \\
\text { mesh }\end{array}$ & $\mathrm{H}$ & $\mathrm{T}$ \\
\hline
\end{tabular}

${ }^{*} \mathrm{H}$, horizontal orientation; I, inclined orientation; ${ }^{* * S S}$, steady state; and $\mathrm{T}$, transient.

Table 2. An overview of some mathematical studies on heat pipes. 
As shown in Table 2, the three-dimensional model received a little attention compared to the two-dimensional model. Additionally, most of the studies addressed horizontal heat pipes that cover both transient and steady-state cases.

\section{Heat pipe for computer cooling applications (desktop and notebook)}

Due to the high effective thermal conductivity of heat pipes compared to that of traditional heat sinks, heat pipes have been proposed and selected for electronic cooling. Therefore, the heat pipe transfers and dissipates the heat very fast. Many researchers focused their studies on using the heat pipe for cooling of electronic devices, and all of them proved that the heat pipe is the best tool for cooling the electronic devices such as desktop and notebook computers. Cooling fins equipped with heat pipes for high power and high temperature electronic circuits and devices were simulated by Legierski and Wiecek [43], and the superiority of the proposed system over the traditional devices was demonstrated. Kim et al. [44] developed a cooling module in the form of remote heat exchanger using heat pipe for Pentium-IV CPU as a means to ensure enhanced cooling and reduced noise level compared to the fan-assisted ordinary heat sinks. Saengchandr and Afzulpurkar [45] proposed a system that combines the advantages of heat pipes and thermoelectric modules for desktop PCs. As shown in Figure 10, the usage of the heat pipes with heat sink could enhance the thermal performance [46].

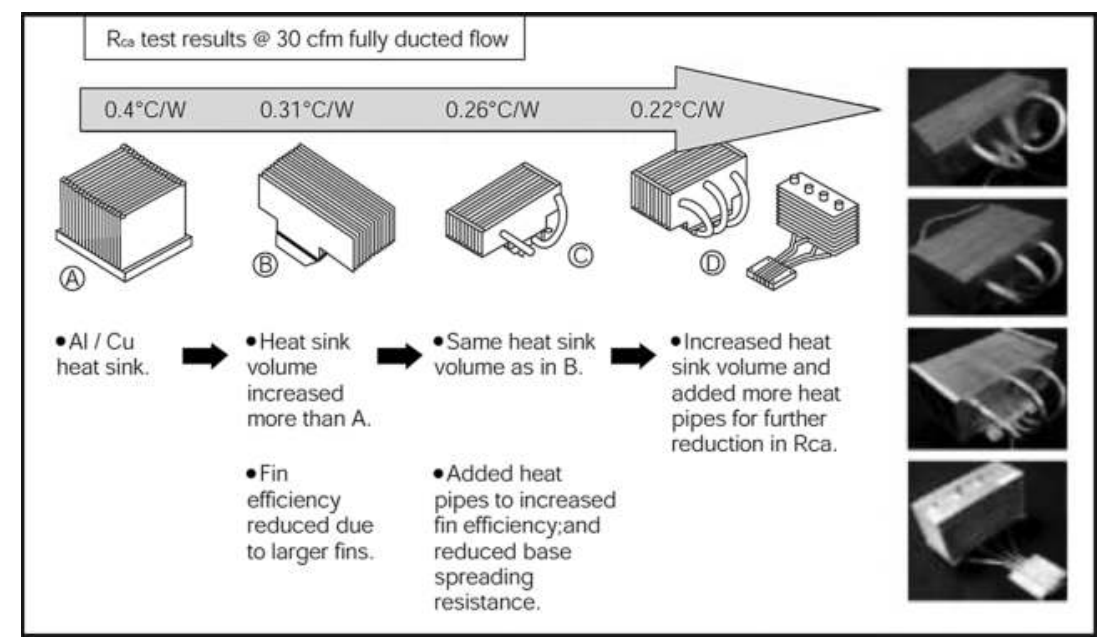

Figure 10. Heat pipe heat sink solution for cooling desktop PCs [47].

$\mathrm{Yu}$ and Harvey [47] designed a precision-engineered heat pipe for cooling Pentium II in Compact PCI. In this work, the design criteria, such as the maximum temperature, thermal transfer plate with a heat load, the maximum ambient air temperature, and the total thermal resistance of the solution, were considered for the processor module. It was observed that both 
thermal and mechanical management of the system was improved using the heat pipe. Kim et al. [44] presented the heat pipe cooling technology for CPU of desktop PC. They had developed a cooler using heat pipe with heat sink to decrease the noise of the fan. Results showed that the usage of heat pipe for desktop PC CPU cooling would increase the dissipated heat without the need for high speed fan. Thus, the problem of the noise generated by the traditional heat sink cooling was solved. Additionally, Closed-end Oscillating Heat pipe (CEOHP) used for CPU cooling of desktop PC was presented by Rittidech and Boonyaem [48]. As shown in Figure 11, the CEOHP kit is divided into two parts, i.e., the evaporator is $0.05 \mathrm{~m}$ long and a condenser section is $0.16 \mathrm{~m}$ long with and a vertical orientation. They selected R134a as the working fluid with filling ratio of $50 \%$. The CEOHP kit should transfer at least $70 \mathrm{~W}$ of heat power to work properly. The CPU chip with a power of $58 \mathrm{~W}$ was $70^{\circ} \mathrm{C}$. The results indicate that the cooling performance increases when the fan speed increases, where the fan speed of 2000 and $4000 \mathrm{rpm}$ were employed. The thermal performance using CEOHP cooling module was better than using conventional heat sink.

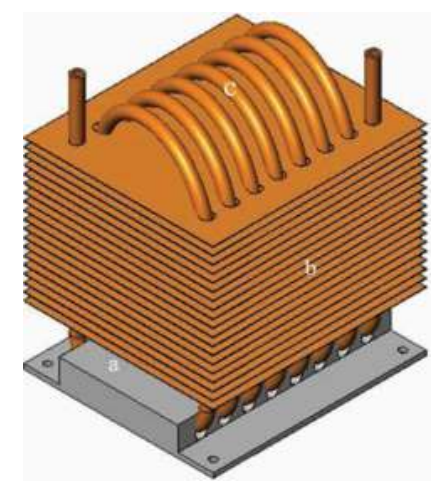

Figure 11. Prototype: (a) aluminum base plate, (b) copper fin, (c) CEOHP. [49].

Recently, heat sinks with finned U-shape heat pipes have been introduced for cooling the highfrequency microprocessors such as Intel Core 2 Duo, Intel Core 2 Quad, AMD Phenom series, and AMD Athlon 64 series, as reported by Wang et al. [49], Wang [50], and Liang and Hung [51]. Wang et al. [49] experimented on the horizontal twin heat pipe with heat sink. The heat input was transferred from CPU to the base plate and from the base plate to the heat pipes and heat sinks simultaneously. The heat was dissipated from fins to the surrounding by forced convection. As shown in Figure 12, experiments were conducted in two stages, in which the first stage measured the temperature for heat pipes only to calculate its thermal resistance. The second stage aimed to measure the temperature for heat sink without and with heat pipes in order to calculate their thermal resistances. It was observed that $64 \%$ of the total dissipated heat was transported from CPU to the base plate and then to fins, whereas $36 \%$ was transferred from heat pipes to fins. The lowest value of the total thermal resistance for the heat pipes with heat sink was $0.27^{\circ} \mathrm{C} / \mathrm{W}$. 


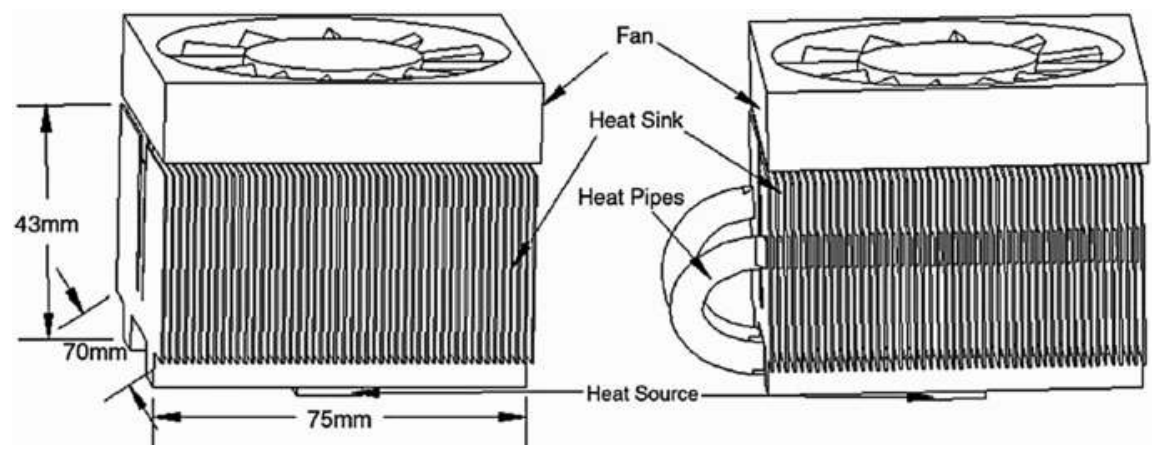

Figure 12. Heat sink without and with embedded heat pipes [50].

The investigations by Elnaggar et al. [52] on the experimental and finite element (FE) simulations of vertically oriented finned U-shape multi-heat pipes for desktop computer cooling are shown in Figure 13a. The total thermal resistance was found to decrease with the increase in heat input and coolant velocity. Moreover, the vertical mounting demonstrated enhanced thermal performance compared with the horizontal arrangement. The lowest total thermal resistance achieved was $0.181^{\circ} \mathrm{C} / \mathrm{W}$ with heat load of $24 \mathrm{~W}$ and coolant velocity of $3 \mathrm{~m} / \mathrm{s}$. This study was further pursued by Elnaggar et al. [53] to determine the optimum heat input and the cooling air velocity for vertical twin U-shape heat pipe with the objective of maximizing the effective thermal conductivity as shown in Figure 13b.
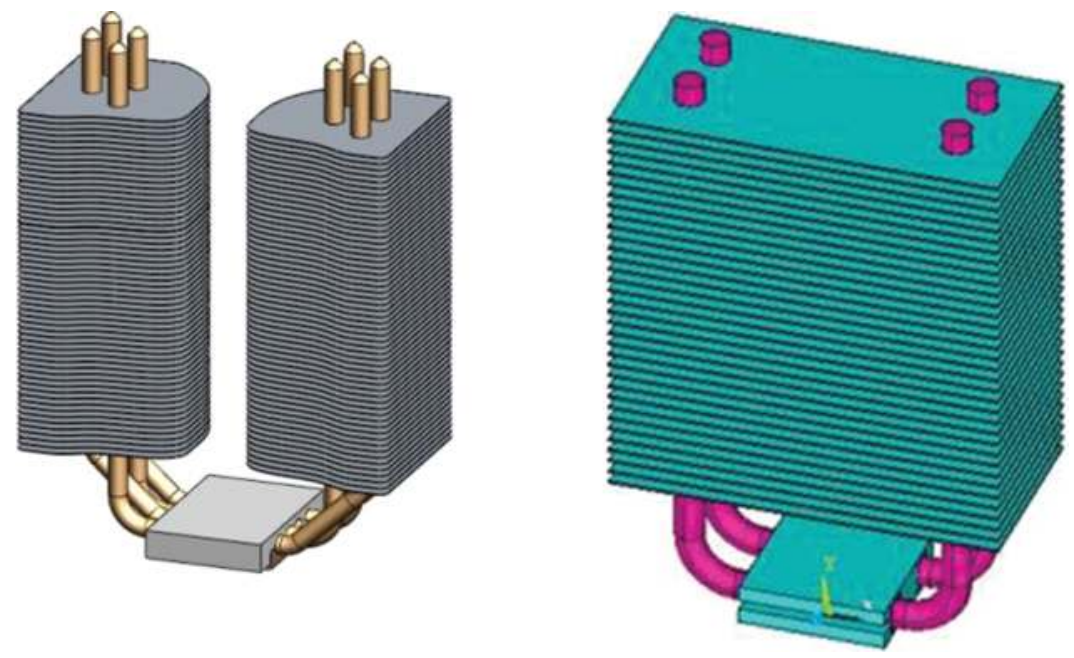

Figure 13. Finned U-shape heat pipe for desktop computer cooling [53, 54]. (a) Finned U-shape multi-heat pipe [53]. (b) Finned U-shape twin heat pipe [54]. 
A summary of studies on heat pipe with heat sink for CPU PC cooling are listed in Table 3.

\begin{tabular}{lllll}
\hline Author & Orientation & Heat pipe shape & No. of heat pipe & Total thermal resistance \\
\hline Kim et al. [44] & Horizontal & L-shape & 3 & $0.475^{\circ} \mathrm{C} / \mathrm{W}$ \\
Wang et al. [49] & Horizontal & U-shape & 2 & $0.27^{\circ} \mathrm{C} / \mathrm{W}$ \\
Wang [50] & Horizontal & U-shape & 2 and 4 & $0.24^{\circ} \mathrm{C} / \mathrm{W}$ \\
Liang and Hung [51] & Horizontal & U-shape & 1 & $0.5^{\circ} \mathrm{C} / \mathrm{W}$ \\
Wang [54] & Vertical & L-shape & 6 & $0.22^{\circ} \mathrm{C} / \mathrm{W}$ \\
Elnaggar et al. [52] & Vertical & U-shape & 4 & $0.181^{\circ} \mathrm{C} / \mathrm{W}$ \\
Elnaggar et al. [53] & Vertical & U-shape & 2 & $0.2^{\circ} \mathrm{C} / \mathrm{W}$ \\
\hline
\end{tabular}

Table 3. A summary of studies on heat pipe with heat sink for CPU PC cooling.

The following conclusions can be derived from the summary of heat pipe with heat sink used in CPU PC cooling:

- The performance of heat sink with heat pipes is much more efficient compared to heat sink without heat pipes.

- Orientation of heat pipe plays a vital role in which the vertical mounting could enhance the heat pipe performance compared to the horizontal arrangement.

- Multi heat pipe leads to a remarkable decrease in thermal resistance, the matter which improves heat pipe efficiency

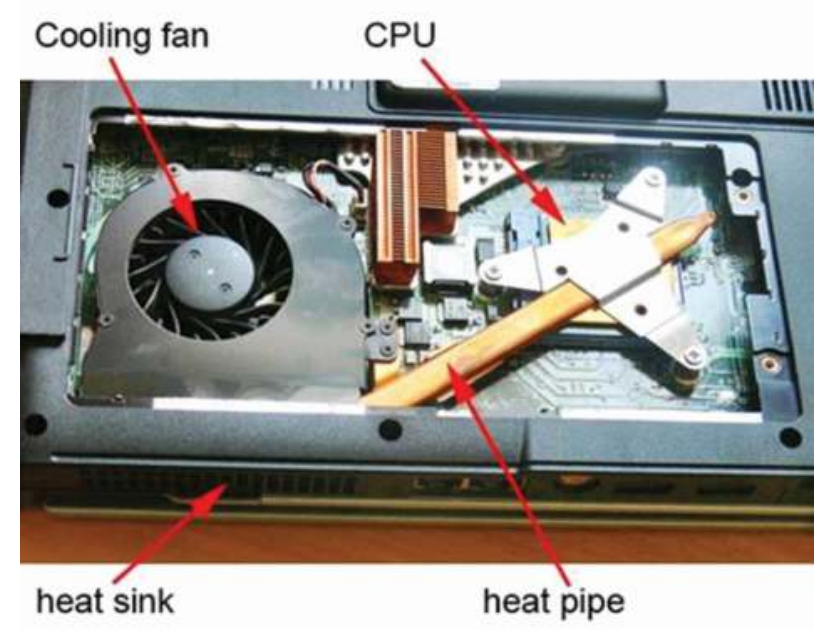

Figure 14. Laptop's cooling using a heat pipe with heat sink [56]. 
The processor's surface in notebook or laptop computers, where most heat is generated, is usually small approximately $10 \mathrm{~mm} \times 10 \mathrm{~mm}$. For useful cooling, the heat must spread over a larger surface area away from the processor, as the space available near the processor is limited as shown in Figure 14. Therefore, heat must be drawn from the processor and conveyed to a place from where it can be dissipated by conventional means. This task is successfully achieved by a heat pipe as it can be accommodated in a highly constrained space in such a way that its evaporator section communicates with the heat source while the finned condenser section is exposed to the sink [55].

\section{Conclusion}

In this chapter, we presented a TDP for cooling the CPU, cooling methods of electronic equipments, heat pipe theory and operation, heat pipes components, such as the wall material, the wick structure, and the working fluid. Moreover, we reviewed experimentally, analytically and numerically the types of heat pipes with their applications for electronic cooling in general and the computer cooling in particular. Clearly, the heat pipe can be regarded as a promising way for cooling electronic equipments. Due to its simplicity, it can work in any orientation and can transfer heat from a place where there is no opportunity and possibility to accommodate a conventional fan, such as notebooks or laptops. Finally, we believe this work would definitely open ways for further research in accordance with the growing attention for the use of heat pipes in electronic cooling.

\section{Author details}

Mohamed H.A. Elnaggar* and Ezzaldeen Edwan

*Address all correspondence to: mohdhn@yahoo.com

Palestine Technical College, Deir EL-Balah, Gaza Strip, Palestine

\section{References}

[1] Ma SP, Park KM, Joung W, Lee J. Operating Characteristics of a Loop Heat Pipe with a Novel Flat Evaporator. 10th International Heat Pipe Symposium. 2011.

[2] Mahajan R, Chia-pin C, Chrysler G. Cooling a microprocessor chip. Proceedings of the IEEE. 2006; 94(8): 1476-1486.

[3] Intel® Core $^{\mathrm{TM}}$ i5-3400 Desktop Processor Series. [Available from: http://ark.intel.com/ products/series/64902]. 
[4] Smith M. What Is Thermal Design Power? [Available from: http://www.makeuseof.com/tag/thermal-design-power-technology-explained/]. 2011.

[5] Ledezma G, Bejan A. Heat sinks with sloped plate fins in natural and forced convection. International Journal of Heat and Mass Transfer. 1996; 39(9): 1773-1783.

[6] Suzuki M, Hirano M. Fan-less Cooling Technology for Notebook Computers. Fujitsu Scientific \& Technical Journal. 1998; 34(1): 87-95.

[7] Ismail MA, Abdullah MZ, Mujeebu MA. A CFD-based experimental analysis on the effect of free stream cooling on the performance of micro processor heat sinks. International Communications in Heat and Mass Transfer. 2008; 35(6): 771-778.

[8] Webb RL. Next Generation devices for electronic cooling with heat rejection to air. Journal of Heat Transfer. 2005; 127(1): 2-10.

[9] Chang Y-W, Cheng C-H, Wang J-C, Chen S-L. Heat pipe for cooling of electronic equipment. Energy Conversion and Management. 2008; 49(11): 3398-3404.

[10] Scott D, Garner PE. Heat Pipes for Electronics Cooling Applications. Electronics Cooling Magazine, Thermacore Inc. 1996.

[11] Kreith F, Bohn MS. Principles of Heat Transfer. Sixth edn. Pacific Grove, CA: Brooks/ Cole. 2001.

[12] Peterson GP. An Introduction to Heat Pipes: Modeling, Testing, and Applications. New York: John Wiley \& Sons, Inc. 1994.

[13] Nemec P, Čaja A, Malcho M. Mathematical model for heat transfer limitations of heat pipe. Mathematical and Computer Modelling. 2013 Jan 31;57(1):126-136.

[14] Yeh L-T, Chu RC. Thermal Management of Microelectronic Equipment: Heat Transfer Theory, Analysis Methods, and Design Practices. New York: ASME Press. 2002.

[15] Heat Pipe Wick Structures Exposed: Sintered, Groove and Mesh. [Available from: http://www.frostytech.com/articleview.cfm?articleID=2466] 2009.

[16] Leong KC, Liu CY, Lu GQ. Characterization of sintered copper wicks used in heat pipes. Journal of Porous Materials. 1997; 4(4): 303-308.

[17] Zhang Y, Faghri A. Numerical simulation of condensation on a capillary grooved structure. Numerical Heat Transfer, Part A: Applications. 2001; 39(3): 227-243.

[18] Ahamed MS, Mochizuki M, Mashiko K, Saito Y, Mabuchi T, Horiuchi Y. Experimental Study of Thin Flat Heat Pipe with a Special Fiber Wick Structure. 9th International Heat Pipe Symposium. 2008.

[19] Wong S-C, Kao Y-H. Visualization and performance measurement of operating meshwicked heat pipes. International Journal of Heat and Mass Transfer. 2008; 51(17-18): 4249-4259. 
[20] Liou J-H, Chang C-W, Chao C, Wong S-C. Visualization and thermal resistance measurement for the sintered mesh-wick evaporator in operating flat-plate heat pipes. International Journal of Heat and Mass Transfer. 2010; 53(7-8): 1498-1506.

[21] Dunn PD, Reay DA. Heat Pipes. fourth Oxford, UK: Pergamon Press. 1982.

[22] Uddin A, Feroz C. Effect of working fluid on the performance of a miniature heat pipe system for cooling desktop processor. Heat and Mass Transfer. 2009; 46(1): 113-118.

[23] Fadhil OT, Saleh AM. Thermal performance of a heat pipe with sintered powder metal wick using ethanol and water as working fluids. Anbar Journal for Engineering Sciences. 2011; 4(1): 62-71.

[24] Blog C. Heat Pipes and Vapor Chambers - What's the Difference? [Available from:http://celsiainc.com/blog-heat-pipes-and-vapor-chambers-whats-the-difference/].

[25] El-Genk MS, Lianmin H. An experimental investigation of the transient response of a water heat pipe. International Journal of Heat and Mass Transfer. 1993; 36(15): 38233830 .

[26] Said SA, Akash BA. Experimental performance of a heat pipe. International Communications in Heat and Mass Transfer. 1999; 26(5): 679-684.

[27] Wang Y, Vafai K. An experimental investigation of the thermal performance of an asymmetrical flat plate heat pipe. International Journal of Heat and Mass Transfer. 2000; 43(15): 2657-2668.

[28] Carbajal G, Sobhan CB, "Bud” Peterson GP, Queheillalt DT, Wadley HNG. A quasi-3D analysis of the thermal performance of a flat heat pipe. International Journal of Heat and Mass Transfer. 2007; 50(21-22): 4286-4296.

[29] Hung YM, Seng Qb. Effects of geometric design on thermal performance of star-groove micro-heat pipes. International Journal of Heat and Mass Transfer. 2011; 54(5-6): 11981209.

[30] Zhang Y, Faghri A. Advances and unsolved issues in pulsating heat pipes. Heat Transfer Engineering. 2008; 29(1): 20-44.

[31] Nine MJ, Tanshen MR, Munkhbayar B, Chung H, Jeong H. Analysis of pressure fluctuations to evaluate thermal performance of oscillating heat pipe. Energy. 2014; 70(0): 135-142.

[32] Charoensawan P, Khandekar S, Groll M, Terdtoon P. Closed loop pulsating heat pipes: Part A: parametric experimental investigations. Applied Thermal Engineering. 2003; 23(16): 2009-2020.

[33] Laun FF, Taft BS . Experimental investigation of in situ pressure measurement of an oscillating heat pipe. Frontiers in Heat Pipes. 2014; 5(8): 1-5. 
[34] Zhu N, Vafai K. Analysis of cylindrical heat pipes incorporating the effects of liquidvapor coupling and non-Darcian transport--a closed form solution. International Journal of Heat and Mass Transfer. 1999; 42(18): 3405-3418.

[35] Nouri-Borujerdi A, Layeghi M. A Numerical analysis of vapor flow in concentric annular heat pipes. Journal of Fluids Engineering. 2004; 126(3): 442-448.

[36] Kaya T, Goldak J. Three-dimensional numerical analysis of heat and mass transfer in heat pipes. Heat and Mass Transfer. 2007; 43(8): 775-785.

[37] Mistry PR, Thakkar FM, De S, DasGupta S. Experimental validation of a two-dimensional model of the transient and steady-state characteristics of a wicked heat pipe. Experimental Heat Transfer. 2010; 23(4): 333-348.

[38] Maziuk V, Kulakov A, Rabetsky M, Vasiliev L, Vukovic M. Miniature heat-pipe thermal performance prediction tool - software development. Applied Thermal Engineering. 2001; 21(5): 559-571.

[39] Suman B, De S, DasGupta S. Transient modeling of micro-grooved heat pipe. International Journal of Heat and Mass Transfer. 2005; 48(8): 1633-1646.

[40] Noh H-K, Song K-S. Temperature distribution of a low temperature heat pipe with multiple heaters for electronic cooling. ETRI Journal. 1998; 20(4): 380-394.

[41] Mahjoub S, Mahtabroshan A. Numerical Simiulation of a Conventional Heat Pipe. Proceedings of World Academy of Science, Engineering and Technology. 2008; 29: 117122.

[42] Ranjan R, Murthy JY, Garimella SV, Vadakkan U. A numerical model for transport in flat heat pipes considering wick microstructure effects. International Journal of Heat and Mass Transfer. 2011; 54(1-3): 153-168.

[43] Legierski J, Wiecek B. Steady state analysis of cooling electronic circuits using heat pipes. IEEE Transactions on Components and Packaging Technologies. 2001; 24(4): 549-553.

[44] Kim K-S, Won M-H, Kim J-W, Back B-J. Heat pipe cooling technology for desktop PC CPU. Applied Thermal Engineering. 2003; 23(9): 11371144.

[45] Saengchandr B, Afzulpurkar NV. A novel approach for cooling electronics using a combined heat pipe and thermoelectric module. American Journal of Engineering and Applied Sciences. 2009; 2(4): 603-610.

[46] Mochizuki M, Saito Y, Kiyooka F, Nguyen T. The Way We Were and Are Going on Cooling High Power Processors in the Industries. 17th International Symposium on Transport Phenomena. 2006.

[47] Yu ZZ, Harvey T. The precision-engineered heat pipe for cooling Pentium II in CompactPCI design. Thermal and Thermomechanical Phenomena in Electronic 
Systems, 2000. ITHERM 2000. The Seventh Intersociety Conference on. 2000; 2: 102-105 vol. 102.

[48] Rittidech S, Boonyaem A, P.Tipnet. CPU cooling of desktop PC by Closed-end Oscillating Heat-pipe (CEOHP). American Journal of Applied Sciences 2005; 2(12): 1574 1577.

[49] Wang JC, Huang H-S, Chen S-L. Experimental investigations of thermal resistance of a heat sink with horizontal embedded heat pipes. International Communications in Heat and Mass Transfer. 2007; 34(8): 958-970.

[50] Wang JC. Novel thermal resistance network analysis of heat sink with embedded heat pipes. Jordan Journal of Mechanical and Industrial Engineering. 2008; 2(1): 23-30.

[51] Liang TS, Hung YM. Experimental investigation on the thermal performance and optimization of heat sink with U-shape heat pipes. Energy Conversion and Management. 2010; 51(11): 2109-2116.

[52] Elnaggar MHA, Abdullah MZ, AbdulMujeebu M. Experimental analysis and FEM simulation of finned U-shape multi heat pipe for desktop PC cooling. Energy Conversion and Management. 2011; 52(8-9): 2937-2944.

[53] Elnaggar MHA, Abdullah MZ, Mujeebu MA. Experimental investigation and optimization of heat input and coolant velocity of finned twin U-shaped heat pipe for CPU cooling. Experimental Techniques. 2011: In press.

[54] Wang JC. L-type heat pipes application in electronic cooling system. International Journal of Thermal Sciences. 2011; 50(1): 97-105.

[55] Elnaggar MH, Abdullah MZ, Munusamy SR. Experimental and Numerical Studies of Finned L-Shape Heat Pipe for Notebook-PC Cooling. Components, Packaging and Manufacturing Technology, IEEE Transactions on. 2013 Jun;3(6):978-88.

[56] Wyatt G. Why eTray laptop trays don't have fans. [Available from: http:// www.etray.co.uk/etraynews/index.php/why-etrays-dont-have-fans]. 2011. 
